\title{
Musical Structure as Narrative in Rock
}

\author{
John Encarnacao, University of Western Sydney
}

\section{Introduction}

The word narrative is often applied to studies of pop and rock music as an organising principle. Musical eras and stylistic movements are arranged to tell particular histories; the works of a particular artist are construed as tracing a stylistic journey; the life story of an artist is invoked to give greater understanding to this or that album, as in 'that's his divorce album' or 'all her records have been crap since she went to rehab.' In each instance, musical works are woven into a constructed narrative in order to make sense of the history of popular music or of particular repertoires. The intention of this paper is to contribute to a discussion of narrative as it occurs in individual examples of rock music. At this level, the idea of narrative is most readily applied to a song's lyrics-the extent to which linear sense can be made, or the extent to which a recognisable emotional state is evoked. Rather than this, though, my intention is to consider the assumptions of narrative from which the structure of much rock music proceeds.

In particular, this research stands at odds with approaches that concentrate on the lyrical content of rock music. Though a study of song lyrics can provide much insight into the attitudes and philosophies of particular groups of people in particular places at particular times, and even help to shape discourses about culture at a broader level, to ignore the sound of pop and rock tracks is to do them a great disservice. The impact of these pieces fuses sound with ideas embodied in the words. A song lyric need not conform to a 
narrative structure, or make literal sense. Nirvana’s 'Smells Like Teen Spirit' (1991) makes for a telling example. A look at the lyric arguably reveals little literal sense ('a mulatto, an albino, a mosquito, my libido'), but combined with the music, a sense of generational torpor, and (perhaps) a fight against this, seems to be transmitted with great force and atmosphere. More to the point, as is often the case with rock recordings, the sound is not designed so that the lyrics are readily decipherable. To concentrate on the lyrics here is to ignore the basic premise of the recording, and, one might say, rock music in general, which is to evoke a state of mind through sound rather than words alone or as the central element. The importance of lyrical content to the reception of a rock track may be lesser or greater depending on the example, but even the work of that most celebrated of lyricists, Bob Dylan, is conveyed at least as much by the overall sound of the recordings, and the timbre and phrasing of his voice, as through the words themselves, and whatever narrative sense they may or may not make. ${ }^{1}$

Walser (1993: 39-41) cautions against the problems that may be encountered when 'oral modes' such as music, by definition episodic, ephemeral and dynamic, are analysed in terms of literate modes, which are narrative, sequential and static. I agree with him to the extent that analyses of rock music which centre on musical scores or song lyrics fall into this trap, but I also regard as valid Gracyk's assertion (1996: viii-x) that rock as a phenomenon is defined by the primacy of the recording as text. I intend to explore this friction between music as a dynamic entity and rock songs as recorded artefacts. Although many writers are cautious about trying to define a nebulous term such as 'rock music, ${ }^{2}$ for the purposes of this paper, I suggest that instrumentation is key to what is broadly addressed by the term. We might refer to rock music as relying predominantly upon instrumental combinations of (usually electric) guitars, keyboards, drums and singing, is often (but not always) song-oriented, and stylistically descending from American traditions of blues, country and jazz. ${ }^{3}$

\footnotetext{
${ }^{1}$ Two examples of popular music studies (chosen relatively at random, as there are many) that concentrate almost exclusively on the lyrics of songs are Smith (2007) and Adelt (2005). While Smith is engaged in an investigation of history and collective memory, and uses blues recordings from 1924-1941 as a primary source, Adelt, to my mind, mistakes the reading of songs' lyrics for a wholesale engagement with Young's output of the mid-1970s.

${ }^{2}$ Witness Allan Moore, in the opening paragraph of his Rock: The Primary Text: 'I shall begin by refusing to offer a definition, in the belief that all readers will bring with them common-sense, and highly diverse, understandings of what "rock" is to them' (2001: 1).

${ }^{3}$ One of the blind peer-reviewers of this work suggested that rock is 'increasingly experienced as multimedia theatre.' While this is true in many cases, such a consideration is beyond the scope of this paper.
} 
To paraphrase Stephenson (2002: 121-143) is also to recount the accepted wisdom of the basic elements of popular song form. A verse is a section that recurs musically with different lyrics each time, or in at least two instances. A chorus is a section that recurs musically with the same, or similar, lyrics each time. A bridge is a section of contrastin verse-chorus form, it generally only occurs after we hear a verse and chorus, and often only after two verses and choruses; in verse-bridge form, it is the section that contrasts with the verse and for various reasons does not conform to our expectations of a chorus. In verse-bridge form, there is often a refrain, a line or pair of lines that breaks into the form at regular intervals, often as the last line of the verse. ${ }^{4}$ There are other identifiable differences between these types of sections—-for example, choruses and refrains commonly contain the title of a song, and backing vocals often enter at a song's chorus (hence the term). There are generally fewer words in a chorus than a verse as narrative detail gives way to summation or exhortation. Pre-choruses are identifiable as common bridges, of sorts, between verses and choruses. ${ }^{5}$ There are also, of course, exceptions to these guidelines, such as songs with successive choruses that offer different sets of lyrics. By and large, these definitions are workable and provide a basis for what is to follow, but I think it important to consider recordings that pursue strategies for structure that do not fit into these archetypes, and to suggest how such approaches might be collected into new categories. For this, I will use Susan McClary’s idea of 'quest narrative’ (2000). ${ }^{6}$

I am also interested in the idea that structure in music is not simply a linear phenomenon, but also articulated by the character of, and fluctuations in, what I will call 'soundmass,' which may be as readily perceived three-dimensionally, as linearly. Moore's sound-box (2001: 120-126) is a descriptive frame comprised of three axes—vertical,

\footnotetext{
${ }^{4}$ A good example of a refrain is the couplet 'Something is happening here, but you don't know what it is / Do you, Mr Jones?,' from Bob Dylan’s 'Ballad Of A Thin Man.’ Note that a refrain is easily distinguishable from a chorus in that it does not constitute a new section.

${ }^{5}$ Pre-choruses are not included in Stephenson's formulation.

${ }^{6}$ Amongst the literature surveyed for this study, the approaches to the idea of narrative found in essays on Western art music differ greatly from that offered here. For example, Maus (1997) engages with writings that seek to chart the emotional content of pieces of music through the attribution of dramatic characteristics to musical gestures, such as melodies. Nicholls cautions against 'musical narrativization: an interpretative act in which a listener invents an explanatory response to events in a composition' (2007: 300). His own analyses are rather literal in the sense that popular songs that can be conceived of as containing dialogue or discourse between characters are examined for musical support or counterpoint to the storytelling. A similar approach is followed by Neal (2007), with particular attention to narrative or episodic story arcs and their intersections with standard variations of verse-chorus-bridge forms. None of these approaches is adopted here.
} 
horizontal and depth/distance, with which his analyses account for spatiality in the recorded text. I use the term sound-mass to indicate the overall sonic identity of a piece, made up primarily of timbre, dynamics, density and register, parameters which writers such as Middleton (2000) and Moore have identified as often downplayed in musicology's historical bias towards harmony, rhythm and form. As constructs, both the sound-box and sound-mass attempt to deal with the sound of rock music as presented through recordings, rather than (or in Moore's case as well as) progressions of rhythms and harmonies - variations on formulae which tell us only so much. Moore's sound-box is based on 'a model which suggests that the instruments and voices of rock are stratified into relatively discrete layers' (2001: 33), which accord to the functions of rhythm, melody, bass line and harmonic accompaniment. This may be useful for many, even the majority of, rock recordings, but tends not to apply to what I term 'immersive' forms later in this paper. In addition, I argue that some of the recordings discussed here deal with music as a process rather than a mapping of received formal constructs. For this I draw upon Judy Lochhead's concept of forming and formbuilding (1992).

\title{
Quest narrative and song form
}

In Conventional Wisdom (2000), McClary, in defining tonality, and nineteenth-century

Western art music practice as structurally distinct from the blues, writes:

\begin{abstract}
The background of a tonal composition ... proceeds through a series of arrivals, beginning in the tonic key, moving through a few other keys, and returning finally home to the tonic. This background thereby traces a trajectory something like a quest narrative, with return to and affirmation of original identity guaranteed in advance. Whereas in the blues, even narrative lyrics are rendered in strophes that minimize narrativity within the musical process, the linear unfolding of tonality almost always pursues a narrative-like series of dramatic events, regardless of the matter at hand. As anthropologists have pointed out, this kind of orientation with respect to time is so fundamental to those of us shaped by such forms that we tend to dismiss as primitive any cultural practices (whether blues or Philip Glass) based on other assumptions. (McClary 2000: 6667)
\end{abstract}

To take this further, the fundamental principle of quest narrative-that of the establishment of a stable home territory, the process of an adventure or series of episodes away from that territory, and a conclusion which returns 'home'-is common in music, as it is in literature and film. In music, it is certainly not restricted to the Classical and Romantic periods of Western art music that McClary focuses on. Just as sonata form is made up of exposition-development-recapitulation, the standard jazz form of head-solos-head is easily received as a quest narrative. I disagree with McClary's reading of blues structure; I would say that the standard 12-bar form is a 
quest narrative in miniature, beginning and ending on the home chord (I) after venturing forth to chords IV and V. ${ }^{7}$ Although it is, of course, missing the point to analyse blues songs solely in terms of their harmonic content, when the most important content is found (arguably) in the areas of timbre, gesture and groove, and these parameters' interaction with the delivery of the lyric, I make this distinction because of the link between the blues form and the strophic nature of much rock music. Another narrative may often be found in blues performances and recordings (though not always) in the building up of dynamics, gradation of timbre, variation in the density of arrangement, or a combination of any of these, through the duration of a performance or recording.

A consideration of how musical structures are articulated, and the extent to which they accord to the default model of the quest narrative, has the potential to provide us with a useful range of analytical tools. There are various ways in which quest narrative may be articulated in rock music and those recordings that break from this convention of form seem to demand a rethinking of popular music analysis. ${ }^{8}$ Two brief examples ${ }^{9}$ will outline structural norms of rock music that still account for a great deal of practice and that are easily reconciled with the idea of the quest narrative.

\section{Elvis Costello - 'Welcome to the Working Week' (1977): verse/chorus/bridge form as quest narrative}

This recording has a structure typical to pop and rock: verse-chorus-verse-chorusbridge-verse-chorus, though the initial verse is presented at a slower tempo than the rest of the song, and the final chorus is truncated. Each verse-chorus unit ventures out from the home territory of the tonic key (E Major) and a timbre and dynamic of relative repose at the start of the verse to a chorus which is denser, louder, features unison rhythms in the instrumentation, and does not start on the tonic chord as the verse does. The bridge extends this excursion away from home, not touching upon the tonic chord

\footnotetext{
${ }^{7}$ If we read McClary literally, she seems to infer that blues music is not tonal. This has to do with her conception of tonality as including all the mechanisms of nineteenth century Western art music. I do not think for a moment she intends to indicate that the blues as a musical style is atonal. Rather, McClary is working from the idea that tonality in the blues is not functional in the sense of how it operates in Western art music.

${ }^{8}$ The use of the term 'recording' is deliberate. The term 'song' is inadequate here, as songs may be found in various arrangements, performances and recordings, and each version may differ in respect to structure and instrumentation.

${ }^{9}$ I acknowledge that the selection of examples is idiosyncratic. There is no attempt made here to be representative of the broad sweep of styles that tend to be grouped under the term 'rock.' Although further points may be made through the use of examples that are more broadly known, I am satisfied that my purpose is served by any examples that satisfactorily illustrate the argument.
} 
at all and maintaining the thickened texture and heightened dynamic level of the chorus. Note that diatonic harmony is pivotal in delineating the form here, as it often is in recordings that articulate traditional rock music structures.

The experience of the sound-mass of this piece is of an ordered and hierarchical structure that supports the voice and lyric, which is itself very much front and centre. The creamy backing vocals and chiming electric guitars present a non-threatening, sixties-oriented backdrop against which Costello’s snarling vocal throws easy rhymes and non-specific images coated with the envy and spite that helped to define his early image. Driving it all is the quest narrative form, which ensures that the recording peaks at a 'golden-mean' three-quarters of the way through in the bridge section, the point harmonically and dynamically furthest away (though not far at all) from 'home.'

The Kinks - 'Everybody’s Gonna Be Happy' (1965): strophic form as quest narrative. A strophic form in pop/rock is one comprised of a limited number of sections-often two or three- that are repeated in the same sequence throughout the recording. We can call a single instance of this sequence of sections a strophe, and each instance of the strophe may outline a quest narrative. ${ }^{10}$ In this example, the strophe consists of versechorus, each section identifiable through its chord progression:

Verse: C7 / G7 (repeat)

Chorus: $\mathrm{B} b$ / $\mathrm{B} b$ / F / A / D / D / C / G

(all chords are major triads unless indicated otherwise)

The verse, though based on only two chords, sustains interest through a three part internal form, the first of which is the verse proper (with different lyrics each time), and the second ('I know') and third ('Come on baby ...') of which are refrains. There is ambiguity over which of the two chords - both sevenths - is the tonic, or home, until the final three chords of the chorus point towards G. Regardless, the repetition of these two chords constitutes a home territory from which the $\mathrm{B} b$ that starts the chorus ventures sharply away. Although relatively concise, the harmonic disruption of the chord progression of the chorus in the context of the repetition of the verse is dramatic, and there is a sense of order being restored upon the resumption of the verse.

\footnotetext{
${ }^{10}$ In the case of twelve-bar blues form, the words strophe, stanza and verse are often interchangeable due to the lack of a contrasting section.
} 
The syncopation in the drums and guitars on this recording, along with its brisk tempo, make it a dance track. This is reinforced by the rhythmic contrast between verse and chorus, with the Latin-clave-like syncopated snare of the verses giving way to urgent clapping on every beat in the chorus. The rhythm arrangement mirrors the underlying imperative of the quest narrative structure, which creates a peak of excitement through each chorus's excursion away from the home territory. Though the vocal sits atop the sound-mass - as is the case with virtually all pop and rock recordings up to 1966-it functions more as party-maker ('I know,' 'C'mon baby,' the goodwill of the song's title) than Costello's combination of image and emotion. Though the feeling is more participatory than in the Costello track, the quest narrative form navigates us through the peaks and troughs of intensity.

In their brevity, the sketches above ignore some important musical phenomena. Instrumentation, arrangement and timbre are taken into account, but more concentration on these aspects might yield very differently nuanced results. Also, instrumentation, harmony and musical gesture go a long way towards defining musical style. We might describe the Costello track as country rock, and the Kinks track as beat-group rock ' $n$ ' roll. Entirely different analytical threads might be pursued along these lines that are beyond the scope of this paper.

\section{Three categories of non-narrative rock song structure}

Judy Lochhead calls upon unpublished writings of Leo Trietler for a general definition of form:

In a chapter titled "The Shape of Time", he defines form as "the organization of periods of time with change and the effect of change,” (Trietler 1976). Form, then, concerns the organizational relations of parts to other parts and of parts to whole, such relationships obtaining among units of a relatively moderate to long duration. (Lochhead 1992: 133)

Helpfully broad, applicable not only to music but to any form which is time-based, the emphasis on 'change and the effect of change' reminds us of the inescapability of the experience of time-based forms as linear. In response to this, and what she terms the 'Aristotelian principles of tragedy: specifically, a temporal form should have a beginning, middle, and end,' Lochhead suggests that 'discussions of form in general and analyses of specific formal instances often do not account for the "building-up" of a whole by the accumulation of parts' (Lochhead 1992: 135). She calls this 'forming,' or 
'formbuilding.' This accumulation of parts may be considered in numerous ways; for Lochhead, in her consideration of pieces by Joan Tower, it has to do with the way in which material returns and is transformed within a score. For our purposes, we might consider the layering of the recording process in which a form is built 'vertically' and in terms of depth-of-field through the construction of a distinctive sound-mass. This is the case particularly with the immersive form of Animal Collective's 'People,' but also with the single-cell forms of Pink Floyd's 'Obscured By Clouds' and Smog's 'All Your Women Things.' We may also invoke the idea of formbuilding in the sense of the block-like addition of section after section in the labyrinth form of Scout Niblett's 'Drummer Boy.'

\section{Labyrinth forms}

I coined this term when analysing some recent independent 'new folk' music, identifying structures which combine numerous sections in such a way that the terms verse, chorus, and bridge are inadequate as descriptors. ${ }^{11}$ As well as featuring a greater number of distinct sections than are commonly found in pop and rock songs, these forms often do not return to their starting points, and so are irreconcilable with the idea of quest narrative. While quest narrative forms in rock music are often episodic, they are homogenously so; labyrinth forms tend to juxtapose episodes in ways that create unfamiliar shapes.

Labyrinth forms share many characteristics with through-composed works. Each meanders through sections without the sorts of repetition or formal plan found in more traditionally structured works. The idea of labyrinth forms is particular to pop/rock/song-based forms in that there often is repetition of sections, but this repetition is handled in such a way that the usual patterns concerning verses, choruses and bridges are not found.

\section{Scout Niblett - 'Drummer Boy' (2003) ${ }^{12}$}

There are six distinct sections here: five sections proper, and a brief coda. As neither of the first two sections of the recording is returned to once left, there is no feeling of 'home territory.' Each successive section strikes the listener as a new place, resulting in

${ }^{11}$ See Encarnacao (2009: 64, 89-92, 101), in which the term 'labyrinth form' is applied to recordings by Kes and Faun Fables.

${ }^{12}$ For an analysis of this song and Niblett's approach on I Conjure Series EP (2003) and I Am (2003), see Encarnacao (2007). 
a structure that is truly episodic, yet, musically speaking, does not subscribe to a traditional sense of narrative. A comparison between the structure of this recording and the two already discussed is instructive:

\begin{tabular}{|c|c|c|}
\hline Recording title & Sectional structure & Analysis \\
\hline $\begin{array}{l}\text { 'Welcome to the } \\
\text { Working Week' }\end{array}$ & $\mathrm{A}-\mathrm{B}-\mathrm{A}-\mathrm{B}-\mathrm{C}-\mathrm{A}-\mathrm{B}$ & $\begin{array}{l}\text { Verse }(\mathrm{A}) \text { - chorus }(\mathrm{B}) \text { - bridge }(\mathrm{C}) \\
\text { form. Each verse-chorus unit } \\
\text { outlines a quest narrative, and the } \\
\text { bridge comprises the furthest point } \\
\text { away from the point of origin. }\end{array}$ \\
\hline $\begin{array}{l}\text { 'Everybody’s Gonna Be } \\
\text { Happy' }\end{array}$ & $\begin{array}{l}\text { (intro on } A)-A-B-A- \\
B-A-B-B-A \text { (fade). }\end{array}$ & $\begin{array}{l}\text { Strophic form. The strophe consists } \\
\text { of verse (A) - chorus (B). Each } \\
\text { strophe outlines a quest narrative. }\end{array}$ \\
\hline 'Drummer Boy' & $\begin{array}{l}A-B-C-D-C-D-C \\
-E-F(\text { coda })\end{array}$ & $\begin{array}{l}\text { None of these sections is readily } \\
\text { identifiable as verse or chorus. } \\
\text { Without a return to the point of } \\
\text { origin or subscription to the types } \\
\text { of sections we expect in rock } \\
\text { recordings, there is no sense of } \\
\text { quest narrative articulated by the } \\
\text { structure. }\end{array}$ \\
\hline
\end{tabular}

In the Costello and Kinks tracks, the alternation of sections A and B is integral to their definition as verses and choruses and helps to cement the idea of a place of origin, a move away from that place, and a return. In 'Drummer Boy' we hear four vastly contrasting sections before any of them is repeated, and neither the $\mathrm{C}$ nor $\mathrm{D}$ section functions as verse or chorus. Additionally, the functional diatonic harmony of the first two examples is not evident in 'Drummer Boy,'13 and this is underlined by the fact that each section is in a different tempo. These aspects upset any traditional notion of narrative as we have come to expect it to operate in song form. ${ }^{14}$

In terms of sound-mass, while each section works within a standard kit of rock instrumentation - vocals, guitars, drums - the lack of continuity between sections means that the listener is constantly readjusting to different sound-masses which individually carry connotations of the confessional singer-songwriter (A), indie/post-rock (B), hard rock (C), outsider music (D and E) and punk (E). These are not exercises in musical style, it would seem, but rather a through-composed approach to the momentary demands of mood and text. While we might be able to plot a trajectory of intensity

\footnotetext{
${ }^{13}$ Sections A, C, D and F all to some extent revolve around the pitch of E, but section B is chromatic and comes to rest on an $\mathrm{E} b 7$ chord, and the riff of section $\mathrm{E}$ has a tonal centre of $\mathrm{F}$, so the idea of a tonal centre of $\mathrm{E}$ for the track is much disrupted.

${ }^{14}$ This is ironic, as part of the lyric concerns a quest: 'No mortal man has yet succeeded in climbing the big glass mountain. / "I know" said the drummer boy "but my heart is stout and determined / and I long for adventure,"’
} 
through the progression of these sections that accords to a sense of narrative, with the template of traditional rock forms as the backdrop to the performance, we are struck mostly by the audacity of the dynamic and stylistic shifts.

\section{Single-cell forms.}

Some rock recordings avoid the quest narrative through being completely comprised of repeated iterations of a single musical idea or tonal area. This may take the form of a riff, chord progression or drone.

\section{Pink Floyd - 'Obscured By Clouds’ (1972)}

This track might be described as a restrained guitar solo over a pulsed drone. Without any alternation of sections, or a strophe, and especially with the track beginning and ending with fades, we could be hearing an excerpt from a much larger, perhaps endless form. The music is presented as a process, rather than having a beginning-middle-end reinforced by formal divisions. The complete lack of harmonic movement helps to establish the sense of a prolongation of a single moment or situation, rather than a progression of episodes or a number of recurring scenes symptomatic of quest narrative structures. Just as pivotal is the lack of variation in instrumentation, timbre and the articulation of rhythm. All of these musical phenomena result in our experience of the track as sound-mass. This is in distinction to the foregrounding of melodic and rhythmic characteristics that traditionally help to articulate quest narrative form in rock music.

It might be possible to map some sort of narrative structure onto the use of register in the lead guitar part, but without the landmarks we usually find in the areas of harmony, instrumentation and timbre, this would be a relatively obscure approach. 'Obscured By Clouds' might also be considered an 'immersive' form (see below), although the mix level of the lead guitar situates it as the lead instrument, much like the vocal in the majority of pop and rock recordings. The presence of a clear lead instrument or vocal in a recording takes us away from immersion as we become spectators to the actions of the lead part as protagonist.

\section{Smog - 'All Your Women Things' (1996) $)^{15}$}

In what is a common approach for this artist, this recording repeats a single three-chord progression for the entirety of its seven-minute duration. While this progression quickly

${ }^{15}$ Again, for a discussion of Smog/Bill Callahan's approach, see Encarnacao (2007). 
establishes a sense of 'home,' the lack of a contrasting section results in the feeling of the song 'not going anywhere.' That is, as with the Pink Floyd example, the expectation of 'change or the effect of change' is thwarted. There is no poetic form to the lyric to help further divide the piece into sections, even though there are some lines that recur.

The slow tempo, smooth timbres of acoustic guitar and cello, the low register of the voice, and the constant gestural and harmonic repetition invite readings of depression, regret, comfort, even sedation, from the sound-mass. There is an intimacy to the dry sound, close miking, and delivery of Bill Callahan's voice that draws our focus towards both the vocal and the lyrics. Although swells and dips in the sound-mass are achieved through the addition and subtraction of instrumental layers, and at some level we may perceive these as contributing to a 'journey,' the resistance to sectional change is highly unusual in rock song form and focuses the listener on a static emotional state. In fact, although the static emotional state is a common gambit in pop and rock lyrics, this stasis is generally juxtaposed with the contrast between sections that results in a sense of musical narrative. In 'All Your Women Things,' the sense of tableau or frozen moment of the lyric is mirrored by the structure of the recording. This underlines the extent to which (at least) two streams of narrative are often in operation, and in contradiction, in rock recordings - the quest narrative driven by the imperatives of sectional contrast and a piece’s climax, and the situation or emotional state offered by the lyric.

\section{Immersive forms}

In this type, sectional contrasts that are generally associated with narrative structure may be present but are overshadowed by the character of the sound-mass. A concentration on timbre and texture pushes harmonic elements, a definitive signifier of sectional change, into the background. The voice tends to be a strand in the texture not as differentiated from the rest of the mix, and not as high in the mix, as we are used to in the context of quest narrative forms. The stratification of texture identified by Moore and heard clearly in the examples thus far is compromised, even obliterated in some cases. A feeling of immersion in the sound-mass can result in a more participatory response to the work and encourages more of a physical and sensual interaction than the emotional and intellectual responses prompted by quest narrative forms. This is not to say that physical, sensual, emotional and intellectual responses are separable, but that immersive forms have a particular appeal to the physical and sensual. 
Theredsunband - 'Pavement' (2003)

The sound-mass here is made up of a highly distorted guitar with very little treble, two languid voices (one female, one male), drum-kit and tambourine. Though the form is punctuated by the refrain, which features the song's title, the experience of the track is perhaps more of its sound-mass than the succession of sections or musical ideas. A verse/bridge form is buried in the sound, the bridge discernible through a subtle change in melody, but the sectional contrast is obscured by the accompaniment, which remains the same for the bridge as the verse. Some sense of climax is discernible in the rise in vocal register and dynamics in the next to last verse/refrain, but this, again, is very subtle compared to the sense of 'quest' embodied in the structures already discussed where sectional contrast is much more clearly articulated. Rather than negotiating a journey with a relatively predictable trajectory, the listener is immersed in the soundmass, coming up for air, as it were, in the textural pause of each refrain.

\section{Animal Collective - 'People' (2006)}

Although layers of instrumentation build up gradually towards the entry of the vocal at two minutes into the recording, rather than forming a procession through contrasting sections, this piece, like 'Pavement' is defined more by its 'three-dimensional' soundmass than by its linear form. Either the receiver (listener seems too restricted a term) of this music surrenders to immersion in the sound-mass, or she is likely to find the repetition unengaging. If pressed, one might say there is a verse ('yeah, yeah-eah/yeah, yeah-eah') and refrain (the 'PEOPLE!!!!!!' scream) structure discernible, but this is buried beneath shimmering guitar textures and blasting drum accents. To define this simple strophe as containing verse and bridge is to stretch the definitions of these terms to breaking point.

One might also argue that the gradual build of layers at the start of the recording, and the quick depletion of them at the end, constitutes a quest narrative articulated by the density of the sound-mass rather than by sections defined by contrasting harmonic progressions. This is the most conspicuous example of those presented here of Lochhead's formbuilding, the layers accreting gradually in such a way that they are relatively indistinguishable to the ear. ${ }^{16}$ This can also be true of strophic forms, where

\footnotetext{
${ }^{16}$ It is worth noting that for Animal Collective around this time (2006), this practice of gradual accretion/depletion of layers, with melodic elements buried, and occasionally rising up through the sonic
} 
the miniature quest narrative of each iteration of the strophe contributes to a larger quest narrative, with density, register, dynamics and timbre articulating a sense of goal and return. While it is important to acknowledge that quest narrative can emerge through the timbral and textural trajectory of the sound-mass (and, in fact, this often happens in tandem with the structural process of quest narrative form), the omission or obfuscation of verse-chorus-bridge or strophic structures in immersive forms leads us to experience rock recordings in an entirely different way.

\section{Conclusion}

All of the examples here that avoid or obscure the conventional structural markers that result in the quest narrative shape downplay harmonic contrast in favour of timbral contrast or an aesthetic that embraces minimal musical means or material. These structures are articulated either through repetition or a drone aesthetic (single-cell and immersive forms) or a multiplicity of sections that explodes conventional rock song form (labyrinth forms). At the risk of drawing the sorts of parallels to classical music that Walser and others have cautioned against, it is as if rock music might be said to be going through a process of exploration not dissimilar to that embarked upon by Western art music composers of the period 1920-1970. As Lochhead asserts, 'The twentieth century ... has witnessed the erosion of the belief that the Aristotelian principles of aesthetics are absolute. Composers have compositionally explored alternate means of temporal organization' (1992: 134). These include, but are not limited to: Edgard Varèse, who initiated a move towards timbre and texture as the chief articulators of structure; the pioneers of musique concrète and electronic composition such as Pierre Henry, Pierre Shaeffer, John Cage and Karlheinz Stockhausen, where harmony and rhythm are often subordinated to the phenomena of sound-as-itself; and minimalists La Monte Young, Steve Reich, Terry Riley and Philip Glass. I am not suggesting that rock music is 'behind,' and 'catching up to' art music, or that art music is the sole bastion of innovation. Pop and rock have always had their own possibilities and effects. It is also apparent that in rock music, structures have always been articulated through sound itself as much as by harmonic or rhythmic organisation.

murk, was as much part of an improvisatory performance practice as studio technique, as witnessed by the author at a concert at Newtown RSL, (‘@Newtown’) Sydney, Australia on 4 November 2006. 
It is hoped that this paper might serve as a starting point for the consideration of the different structural paradigms that can be discerned in popular music. The most obvious antecedents to the examples presented here might be The Velvet Underground and German ('Krautrock') groups such as Can, Faust and Tangerine Dream, all active in the late 1960s and early 1970s, and all of whom experimented with structure. Since that time, the number of rock artists who have made recordings where structures might be best described as labyrinth, immersive, or single-cell, is immense. In particular, there has been a great rise in single-cell and immersive forms in the first decade of the twenty-first century, with new stylistic fusions such as avant-folk (e.g. Six Organs of Admittance, Charalambides), avant- and psychedelic rock (e.g. Akron/Family, Animal Collective, Gang Gang Dance), and punk-art collisions (e.g. Castings, Black Dice). ${ }^{17}$

However, we need not confine ourselves to the fringes of rock music to find use for the formal categories introduced here. The funk of James Brown from the mid-sixties through to the early 1970s (for example) offers another opportunity to consider immersive forms. Though articulated by polyrhythms, we may experience many of these recordings as pulsating sound-masses rather than analyse the rhythmic components. Of course, this is true also of a great number of rock recordings, but most of these are overlaid by the quest narrative structure articulated by verse-chorus-bridge or strophic forms. By contrast, many classic funk sides by Brown-for example, 'Mother Popcorn' (1969) and 'Sex Machine' (1970)_are virtually single-cell forms only broken up by a single detour to a bridge. A study of the structural paradigms presented by electronic dance music, or hip hop, using the categories suggested in this paper, might also be instructive, as it would help to explain the extent to which various examples are related to, rely on, or reject, structural conventions of pop and rock.

One of the most immediate uses of this approach to musical structure might be to rethink the ways in which recordings as texts are related, irrespective of style or genre. That is, the recognition of labyrinth, immersive and single-cell forms might be used to group pieces apart from stylistic types predicated largely by rhythm and gesture. This approach also invites the comparison of examples of rock music with narrative and nonnarrative approaches to other disciplines, particularly film and literature. Straying from

\footnotetext{
${ }^{17}$ The extent to which some of these artists, and/or individual recordings by them, might be described as rock is open to debate.
} 
structural norms might be seen as representative of an approach to the history of a culture, a reluctance on the part of an artist to be aligned too closely to one movement or another.

\section{Acknowledgments}

This essay was completed as part of the Professional Development Program at the University of Western Sydney.

\section{Reference List}

Adelt, U. 2005, “'Hard to Say the Meaning”: Neil Young’s Enigmatic Songs of the 1970s,' Journal of Popular Music Studies, vol. 17, no. 2: 162-174.

Encarnacao, J. 2007, 'Cult Musicians Versus Technology: Transcending Notions of Popular Music as Commodity,' International Journal of Technology, Knowledge and Society, vol. 2, no. 6: 65-73.

Encarnacao, J. 2009, Punk Aesthetics in Independent New Folk, 1990-2008, MA thesis, University of Technology, Sydney. Online, available: http://hdl.handle.net/2100/981 [Accessed 1 Jan. 2011].

Gracyk, T. 1996, Rhythm and Noise: An Aesthetics of Rock. Duke University Press, Durham \& London.

Lochhead, J. 1992, ‘Joan Tower's “Wings” and "Breakfast Rhythms I and II”: Some Thoughts on Form and repetition,' Perspectives of New Music, vol. 30, no. 1: 132-156.

Maus, F. E. 1997 'Narrative, Drama and Emotion in Instrumental Music,' The Journal of Aesthetics and Art Criticism, vol. 55, no. 3: 293-303.

McClary, S. 2000, Conventional Wisdom: The Content of Musical Form. University of California Press, Berkeley.

Middleton, R. 2000, 'Popular Music and Musicology: Bridging the Gap,' in Reading Pop: Approaches to Textual Analysis in Popular Music, (ed.) R. Middleton. Oxford University Press, Oxford, 104-121.

Moore, A. F. 2001, Rock: The Primary Text. Ashgate, Aldershot \& Burlington.

Neal, J. R. 2007, 'Narrative Paradigms, Musical Signifiers, and Form as Function in Country Music,' Music Theory Spectrum, no. 29: 41-72.

Nicholls, D. 2007, 'Narrative Theory as an Analytical Tool in the Study of Popular Music Texts,' Music \& Letters, vol. 88, no. 2: 297-315.

Smith, C. 2007, 'Going to the Nation: the Idea of Oklahoma in Early Blues Recordings,' Popular Music, vol. 26, no. 1: 83-96.

Stephenson, Ken 2002, What To Listen For In Rock. Yale University Press, New Haven \& London.

Walser, R. 1993, Running With The Devil: Power, Gender and Madness in Heavy Metal Music, Wesleyan University Press, Hanover, NH.

\section{Discography}

Animal Collective 2006, ‘People,’ People EP, Spunk.

James Brown 1969, 'Mother Popcorn (You Got to Have a Mother for Me),' King 45 rpm single, collected on The CD of JB (Sex Machine and Other Soul Classics), Polydor, 1985.

James Brown 1970, 'Get Up (I Feel Like Being a) Sex Machine,’ King 45 rpm single, unedited take collected on The CD of JB (Sex Machine and Other Soul Classics), Polydor, 1985.

Elvis Costello 1977, 'Welcome to the Working Week,' My Aim Is True, Stiff.

Bob Dylan 1965, 'Ballad of a Thin Man,’ Highway 61 Revisited, Columbia.

Kinks 1965, 'Everybody’s Gonna Be Happy,' Pye 45rpm single, collected on Greatest Hits, PRT, 1984.

Scout Niblett 2003, 'Drummer Boy,' I Am, Too Pure.

Nirvana 1991, 'Smells Like Teen Spirit,' Nevermind, DGC.

Pink Floyd 1972, 'Obscured By Clouds,' Obscured By Clouds, Harvest.

The redsunband 2003, 'Pavement,' Slanted CD single; also on Peapod 2004, Slanted.

Smog 1996, ‘All Your Women Things,' The Doctor Came At Dawn, Drag City. 